\title{
Educación de Jóvenes y Adultos en Argentina. Historia reciente, sujetos, coyuntura y desafíos
}

\author{
Educação de Jovens e Adultos na Argentina. \\ História recente, sujeitos, conjuntura e desafios \\ Youth and Adults Education in Argentina. \\ Recent history, subjects, conjuncture and challenges \\ ESTHER LEVY \\ Universidad de Buenos Aires, Facultad de Filosofia y Letras, Argentina
}

\begin{abstract}
RESUMEN
Este artículo resume ideas y posicionamientos críticos sobre la Educación de Jóvenes y Adultos (EJA) en la Argentina. Tales ideas son producto de discusiones conceptuales y políticas radicadas en la Facultad de Filosofía y Letras de la Universidad de Buenos Aires donde la autora es investigadora. Estas ideas están también influenciadas por la experiencia en equipos de gestión político pedagógica del Ministerio de Educación Nacional y la militancia sindical que desarrolla la autora. El trabajo contiene precisiones conceptuales sobre la EJA y sus sujetos, la historia reciente de la modalidad y el escenario pedagógico y político actual. En los albores del siglo XXI los cambios en la educación argentina marcaron una etapa de optimismo para la EJA que duró hasta que se produce un giro conservador a fines de 2015 con la llegada al gobierno de la Alianza Cambiemos, una expresión de la derecha democrática que ganó las elecciones por el $51 \%$ de los votos.
\end{abstract}

Palabras clave: Educación. Adultos. Derechos. Política. Neoliberalismo.

\section{RESUMO}

Este artigo resume ideias e posições críticas sobre Educação de Jovens e Adultos (EJA) na Argentina. Essas ideias são produto de discussões conceituais e políticas na Faculdade de Filosofia e Letras da Universidade de Buenos Aires (UBA), onde a autora é pesquisadora e também estão influenciadas pela sua experiência em equipes de gestão político-pedagógica no Ministério da Educação Nacional da Argentina e na militância sindical. O trabalho contém precisões conceituais sobre a EJA e seus sujeitos, a história recente da modalidade e o atual cenário pedagógico e político. Na Argentina, os primeiros anos do século XXI, marcaram uma fase de optimismo para a EJA, que durou até produzida uma virada conservadora no final do ano 2015, com a chegada ao governo da Aliança denominada Cambiemos, expressão da direita democrática que ganhou as eleições nacionais por $51 \%$ dos votos.

Palavras-chave: Educação. Adultos. Direitos. Política. Neoliberalismo.

\begin{abstract}
This article summarizes ideas and critical positions on Youth and Adults Education $(E J A)$ in Argentina. These ideas are the product of conceptual and political discussions at the Faculty of Philosophy and Letters of the University of Buenos Aires, where the author is a researcher. These ideas are also influenced by the experience in pedagogical political management teams of the Ministry of National Education and the union militancy developed by the author. The work contains conceptual precisions about the EJA and its subjects, the recent history of the modality and the current pedagogical and political scenario. At the dawn of the 21 st century, the changes in Argentine education marked a stage of optimism for the EJA that lasted until a conservative turnaround took place at the end of 2015 with the arrival of the Cambiemos Alliance, an expression of the democratic right that He won the elections by $51 \%$ of the votes.
\end{abstract}

Keywords: Education. Adults. Rights. Politics. Neoliberalism. 


\section{INTRODUCCIÓN: PRECISIONES INICIALES}

Los Derechos Humanos constituyen un marco de referencia común basados en normas y valores reconocidos universalmente que plantean obligaciones al Estado para "actuar" de determinada manera o de "abstenerse" de hacerlo en situaciones especificas. Los Estados que adhieren al Pacto Internacional de Derechos Económicos, Sociales y Culturales de 1966 (PIDESC/1966) ${ }^{1}$ tienen la obligación de actuar garantizando la existencia de condiciones necesarias para el ejercicio efectivo los derechos partir de la creación y puesta en marcha de políticas activas. Los DESC son derechos relativos a las condiciones sociales y económicas vinculadas a la dignidad de las personas (salud, trabajo, vivienda, etc., entre otros) y en este sentido son universales, irrenunciables e intransferibles. Así, la educación es un Derecho Humano que, además, no prescribe con la edad. Posiblemente esta sea una aclaración que resulte redundante pero es, sin embargo, necesaria porque desde el sentido común se asocia la educación (o la escuela) a las trayectorias educativas "exitosas", es decir con aquellos que pudieron estudiar cuando estaban en edad escolar. Sin embargo, en Argentina del mismo modo que en la mayoría de los países de la región habitan miles de personas que no han podido ir a la escuela cuando eran niños y/o jóvenes y que hoy son los sujetos - efectivos o potenciales - de la EJA.

Partimos de la idea de que en su condición de derecho, por definición, la educación es política. Se trata de un posicionamiento cargado de ideología que lleva implícita la marca de la emancipación de la mano del pensamiento crítico. Con esta mención ponemos explícitamente en tela de juicio las pretensiones de neutralidad de las posturas liberales que esconden intereses económicos y de poder.

En este artículo se analiza lo que sucedió en la historia reciente de la Educación de Adultos en Argentina entendida como un derecho que no prescribe con la edad de modo de comprender los factores que hoy se constituyen como sus principales desafíos.

La Argentina es un país federal, dividido en 24 Estados provinciales, cuya Capital es la Ciudad Autónoma de Buenos Aires. La Constitución Nacional fue reformada en 1994 introduciendo, entre otros elementos el art. 75 inciso 19 sobre los principios de gratuidad y equidad de la educación publica. El país recuperó la democracia en 1983 luego de 8 años de una sangrienta dictadura cívico

\footnotetext{
${ }^{1}$ Fue adoptado y abierto a la fiema de los Estados el 16 de diciembre de 1966 y entró en vigencia el 3 de enero de 1976. Hasta la fecha ha sido ratificado por más de 160 países. Junto con la Declaración Universal de los Derechos Humanos y el Pacto Internacional de los Derechos Civiles y Económicos conforma la Carta Internacional de Derechos Humanos.
}

militar iniciada el 24 de marzo de 1976 y que dejó un saldo de 30 mil desaparecidos y cientos de exiliados y presos políticos. El gobierno de facto puso en marcha un plan de ajuste de corte liberal forjando las bases del modelo de apertura económica y desmantelamiento del Estado de Bienestar que luego se consolidó en la década del 90 que conocemos como neoliberalismo. Apenas asumió la Junta Militar se abandonó el nacionalismo económico y el proteccionismo productivo local. El lugar del Estado en relación a la política social quedó relegado a contener a los grupos que no lograban sobrevivir a las reglas del mercado (los más pobres de los pobres). Para 1982 el peso de la creciente deuda externa, la administración fraudulenta del Estado en complicidad con el empresariado corrupto, el aumento de la pobreza y la desocupación, además de la derrota en la Guerra de Malvinas en 1982², el poder y la estructura autoritaria de la dictadura fueron resquebrajándose, lo que determinó una pronta salida electoral. En 1983, con el advenimiento de la democracia, comienza a escribirse una nueva etapa en la Argentina, la etapa más larga en Estado de derecho (desde el 10 de diciembre de ese año hasta la fecha sólo se sucedieron gobiernos constitucionales). Hoy la democracia cumple 36 años, está desgastada, cuestionada y deslegitimada pero sigue siendo el sistema político elegido y defendido por la mayoría de los argentinos.

Respecto a la situación social y ocupacional actual, según las fuentes oficiales, - Instituto Nacional de Estadísticas y Censos (INDEC/2018) - la población total del país es de 44.494.502 habitantes (mujeres: 22.670.130 y varones: 21.824 .372 ), la pobreza en el primer semestre de 2018 alcanzó el 27,30\% de la población (12 millones de personas). Si bien la Población Económicamente Activa es de 28 millones, o sea el $64 \%$ del total, los datos de la desocupación son alarmantes: el 9,6\% de la población (12 millones de trabajadores) se encuentra desocupada siendo esta taza la mas alta el 12 años. A su vez, el 35\% de los asalariados son trabajadores precarizados (informales).

En el plano educativo, la Argentina es un país que ha logrado altas tasas de escolarización primaria (llamada fundamental en Brasil) a mediados del siglo XX. Sin embargo, los límites democratizadores de la escuela moderna son claros y visibles. La educación formal se caracteriza por su estructura vertical segmentada con circuitos diferenciados al interior que inciden directamente en las trayectorias educativas de los estudiantes así como también en su inserción laboral futura (BRASLAVSKY, 1985; BAUDELOT; ESTABLET, 1971). Dicho esto, no hay duda que la EJA constituye una de las deudas más

\footnotetext{
${ }^{2}$ Enfrentamiento bélico que duró 2 meses entre Argentina e Inglaterra por las Islas Malvinas las cuales fueron usurpadas por el país europeo en 1833 .
} 
dolorosas de la sociedad moderna: la educación como derecho universal es, hasta ahora, una meta incumplida. Fue a partir de la segunda mitad del siglo XX, cuando el proyecto pedagógico hegemónico entró en crisis y el sistema escolar comenzó a mostrar su incapacidad de retener a los estudiantes ampliando los márgenes de acción y contención de la educación de adultos que recibió a los "desertores", los "expulsados", "los marginados del sistema" (Levy, 2013). Pero, ¿Qué abarca la EJA en Argentina? ¿Cuáles son sus sujetos?

Los que investigamos en este campo sabemos que la definición EJA no es unívoca y que da cuenta de una trama compleja de debates, luchas y definiciones disímiles que revelan los aspectos polisémicos de la categoría en relación con el contexto histórico y social en el que se construyen (CABRERA, 2006). En todo proceso educativo - que es social y político a la vez - el contexto es significativo y cuando el sujeto de esa educación son los jóvenes y adultos pobres y excluidos, más aún (DE LELLA, 2003). Donde se entrecruzan distintas dimensiones de lo social que atraviesan lo que antes era un campo casi exclusivo de la pedagogía o de la psicología evolutiva, es la EJA la que termina dando respuesta a la diversidad lo cual plantea enormes desafíos para la modalidad tales como construir una propuesta curricular adecuada, formar docentes, definir cómo evaluar los aprendizajes, diseñar programas modulares y flexibles, son algunos de los temas que requieren reflexión y propuestas (LEVY, 2013). Lidia Rodríguez, por su lado, la define como

la propuesta de educación de adultos que fue constituyéndose como hegemónica a lo largo del siglo XX $[\ldots]$ es un derivado necesario de un sistema escolar incapaz de completar el proyecto fundacional de "civilizar" ...; es un espacio de cierre del discurso que no abandona (ni perdona) a los que desertan, repiten y no pueden o se resisten a ser incorporados a la cultura escolar moderna, y los transforma en "adultos" y “analfabetos" (RODRÍGUEZ, 1997, p. 290-291).

Si bien sabemos que lo educativo no se limita a las relaciones y escenarios específicamente escolares, sino que se desarrolla el espacio social más amplio y en cada sujeto respecto a los demás (GRAMSCI, 1981), podemos afirmar sin riesgo a equivocarnos que la EJA es siempre un espacio de resistencia, de condensación de expectativas, temores y de nuevas oportunidades. En la actualidad, cualquier definición de sujeto de la EJA incluye una característica distintiva: la heterogeneidad. Es decir, la heterogeneidad respecto a las edades (desde jóvenes/ adolescentes a adultos mayores), a la inserción laboral (desde los que nunca tuvieron un trabajo a aquellos que si lo tuvieron y hoy se encuentran ocupados/desocupados), a los niveles iniciales de escolarización (un mismo nivel de escolaridad no es garantía de conocimientos equiparables), a las diferentes expectativas y motivaciones que tienen para aprender, a las estrategias que han construido para desenvolverse en el mundo, etc.

... el adulto de la educación de adultos no se define por su edad, ni por el grado de desarrollo de sus capacidades. Es, simplemente, un marginado del sistema escolar, al que el discurso pedagógico dominante construye como un sujeto carenciado. Se produce así un efecto de ocultamiento de la capacidad del sistema escolar de producir "marginados educacionales" (RODRÍGUEZ, 1996, p. 83).

En síntesis, creemos que un abordaje de la EJA necesariamente es multidimensional, contiene procesos complejos que la atraviesan y constituyen como un campo específico de la educación y la pedagogía donde la dimensión histórica es inseparable de la dimensión política.

\section{LA EDUCACIÓN DE JÓVENES Y ADULTOS EN LA HISTORIA RECIENTE DE Argentina}

Los procesos políticos, económicos y sociales tienen siempre correlato en las políticas educativas. A los fines de este trabajo realizamos un recorte e identificamos tres momentos o hitos de la historia reciente de la EJA en Argentina de modo de contar con elementos conceptuales y políticos para reflexionar sobre la actualidad y los desafíos de la modalidad. Los tres periodos considerados son: 1973, 1989-2002 y 2003- 2015.

\section{Primer momento: 1973, el Peronismo y la Dirección Nacional de Educación de Adultos (DINEA)}

En 1955 se produjo un Golpe de Estado, autodenominado Revolución Libertadora ${ }^{3}$ cuya escena inaugural fue un bombardeo sangriento sobre la población civil en la Plaza de Mayo. El objetivo fue derrocar al gobierno constitucional de Juan Domingo Perón - electo por segundo mandato - quien fue destituido, encarcelado y proscripto. El mandatario se exilió en España desde donde regresó 18 años después, en junio de 1973, cuando ganó elecciones presidenciales la formula de Héctor J. Cámpora-Vicente Solano Lima, que obtuvo más de 6 millones de votos (49\%). Esta fórmula presidencial

\footnotetext{
3 Nombre con el que se auto nombró la dictadura militar que duró entre 1955 y el 1 de Mayo de 1958, cuando el Presidente Arturo Frondizi (constitucional) asumió a la presidencia y recibió el gobierno de manos del General Pedro Eugenio Aramburu. El propósito del golpe militar era "liberar al país de los excesos del gobiernos de Juan Domingo Perón quien fuera presidente constitucional entre 1946 y 1955 (casi dos mandatos constitucionales).
} 
respondía al Frente Justicialista de Liberación (FREJULI) que no era otra cosa más que el peronismo con otro nombre. Cámpora, el flamante presidente eliminó la proscripción del peronismo propiciando abiertamente el regreso al país de Perón quien detentaba el verdadero poder político (el slogan electoral fue "Cámpora al gobierno, Perón al poder"). El triunfo de Cámpora estuvo marcado por un alto grado de movilización social expresado principalmente en la militancia política juvenil que (jóvenes de los 70) identificada con la consigna "liberación o dependencia" en consonancia con las ideas que atravesaban a América Latina $^{4}$.

La Educación de Adultos durante el breve gobierno de Cámpora (apenas 49 días, del 25 de mayo al 13 de julio de 1973) y unos meses más hasta 1974 constituyó una prioridad político-pedagógica donde la DINEA ocupó un lugar de centralidad. Esta Dirección no era nueva ni nació en democracia, era una construcción burocrática disciplinadota creada en 1968 durante la dictadura del General Onganía y sus lineamientos iban en consonancia con las recomendaciones en la Tercera Reunión Interamericana de Ministros de Educación (1963) realizada en Bogotá donde se decidió que cada país creara un organismo responsable de la educación de adultos en el seno de sus Ministerios de Educación Nacionales. Entre 1969 y 1973 la DINEA estuvo bajo la orbita de la iglesia católica mientras que, en forma paralela y opuesta ideológicamente, se iba gestando un proyecto pedagógico emancipador que tuvo como sujeto al adulto sin escolaridad formal y cuyo eje organizador fue la idea de liberación, inspirada especialmente en los primeros trabajos de Paulo Freire en el exilio. Fue recién en el breve período 73/74 (Cámpora/Perón) cuando estas ideas se articularon en la propuesta político pedagógica del gobierno peronista. Adriana Puiggros plantea que la influencia de la hegemonía de la izquierda peronista "propugnaba una pedagogía nacionalista popular liberadora que sumaba fundamentos de la pedagogía peronista desarrollada entre 1945 y 1955, alguna influencia del liberalismo laico y un gran peso de la pedagogía de la liberación" (PUIGGROS, 1998, p. 160).

Con la refundación "peronista" de la DINEA en 1973 se inauguran experiencias inéditas en el campo de la EJA, modificaciones profundas en los vínculos entre docentealumno, conocimiento-aprendizaje, escuela-comunidad, culturas escolar-cultura popular. La educación era entendida como estrategia para la construcción política y la EJA como herramienta de resistencia cultural del pueblo trabajador. Se abrieron espacios de discusión y

\footnotetext{
4 En el acto de Asunción presidencial estuvieron presentes los presidentes de Chile, Salvador Allende, y de Cuba, Osvaldo Dorticós, junto a más de un millón de militantes peronistas manifestando su apoyo en las calles.
}

problematización de la realidad, criticados y señalaron por los opositores como estrategias que reducían lo pedagógico al proyecto político del peronismo. Se puede coincidir o no con esta crítica, pero es innegable la voluntad transformadora de aquel proyecto que propiciaba la generación de espacios de lucha política y cuyas raíces freireanas marcaron su identidad (LEVY, 2013). La Campaña de Reactivación de la Educación de Adultos para la Reconstrucción (CREAR) fue una de las experiencias más destacadas que llevó adelante la DINEA, inspirada en el método de alfabetización freireano. Siguiendo a Gómez, la CREAR apostaba a una estrategia de reactivación y reformulación de las experiencias de la educación de adultos de la época con un espíritu cuestionador del modelo de acumulación de poder del capitalismo “....adoptó desde sus inicios el concepto de la cogestión, figura que proponía una síntesis entre la acción del Estado y las diversas formas de organización social, ambos inscriptos en el campo de lo popular..." (GOMEZ, 2012, p. 83).

La CREAR adoptó de Freire el método basado en la palabra generadora. Las láminas formaban parte de dicha metodología y eran trabajadas en los encuentros de alfabetización. El espíritu innovador y movilizador en términos políticos estuvo en consonancia con el clima de época que se vivía en América latina. La idea de utopía y emancipación fueron la marca ideológica sobre la cual se construyeron estas experiencias. Lamentablemente, estos impulsos duraron un corto período, dado que la política justicialista que sucedió a la presidencia de Cámpora y, posteriormente a la muerte de Perón (ocurrida el $1 \stackrel{\text { o de }}{ }$ julio de 1974 y que llevó a su esposa y vicepresidenta a asumir la presidencia) determinaron la paralización de muchas acciones de la DINEA, incluidas las de la CREAR; cuestión que se agudizó a partir del golpe de Estado del 24 de marzo de 1976, con su política de exterminio (DE LA FARE; VILLELA PEREYRA, 2011). Es decir, aunque los acontecimientos de violencia política previos al golpe cívico-militar de 1976 ya habían clausurado la viabilidad de la experiencia transformadora de la DINEA (acotada en el tiempo pero profunda en su contenido), la instauración de la dictadura y su política de exterminio físico e ideológico arrasó con las posibilidades de continuidad del proyecto.

\section{Segundo momento: 1989-2001. Neoliberalismo y educación de jóvenes y adultos}

El Dr. Raúl Alfonsín (1983-1989) fue el presidente del retorno de la democracia. Para entonces, la EJA había perdido el potencial transformador de principios de los 70 y se avecinaba un largo período de invisibilización. Durante este gobierno la única política nacional de 
educación de jóvenes y adultos, fue el Plan Nacional de Alfabetización que redujo las acciones del sector a la alfabetización ${ }^{5}$. Si bien Alfonsín cumplió su mandato su salida del gobierno fue anticipada en medio de un proceso hiperinflacionario que llevó a adelantar las elecciones presidenciales. Fue sucedido por Carlos Menem (19891999), quien apenas asumió dejó claro que no comulgaba con las ideas setentistas (aunque era peronista) y avanzó en la recuperación y profundización del proyecto de liberalización económica iniciado con la dictadura cívico militar en 1976.

La impugnación al rol del Estado, sumado a los discursos privatistas fueron los pilares del un proceso de ajuste estructural inimaginable décadas atrás. Se pusieron en marcha programas destinados a crear un orden económico-social orientado al mercado, reduciendo la capacidad de intervención del aparato estatal. Los postulados del Consenso de Washington $(1989)^{6}$ funcionaron como la matriz ideológica de los procesos de avance del capital privado (en desmedro de los intereses públicos) y la reubicación del Estado nacional como gerente de los intereses trasnacionales. El andamiaje normativo que dio sustento al plan reestructurador en Argentina tuvo dos leyes que fueron centrales: la Ley de Reforma del Estado 23.696, sancionada en agosto de 1989 y la Ley de Emergencia Económica 23.697, en septiembre de 1989. La primera posibilitó la reforma de los diferentes sectores del Estado y las privatizaciones de las empresas públicas, mientras que la segunda marcó el rumbo de la apertura y la desregulación de los mercados (LEVY, 2013).

En el ámbito educativo se implementó una reforma estructural cuyo andamiaje legal modificó la fisonomía del sistema en todos los niveles dejando en evidencia los objetivos económicos por encima de los pedagógicos y culturales. La Ley Federal de Educación 24.195/93 - ley "madre" de la Reforma - fue la que marcó los escenarios en la vida cotidiana de las aulas y las organizaciones docentes, generando conflictos y situaciones de desidia como sucedió en la educación de adultos. A partir de 1992 los servicios educativos fueron descentralizados y transferidos a las provincias generando la disolución de las Direcciones Nacionales como era el caso de la DINEA. Cada provincia se responsabilizó de la oferta educativa cuyo sostenimiento contó con contraparte presupuestaria nacional. Dejaron de existir

\footnotetext{
5 Para profundizar sobre el Plan Nacional de Alfabetización y la política educativa durante el gobierno del Dr. Raúl Alfonsín, consultar Wanschelbaum (2012).

${ }^{6}$ Las 10 ideas centrales fueron: Disciplina fiscal; Reordenamiento de las prioridades del gasto público; Reforma Impositiva; Liberalización de las tasas de interés; Una tasa de cambio competitiva; Liberalización del comercio internacional (trade liberalization); Liberalización de la entrada de inversiones extranjeras directas; Privatización; Desregulación; Derechos de propiedad.
}

instancias de concertación de políticas a nivel nacional quedando libradas las decisiones a la voluntad política de los gobiernos provinciales. Durante los años 90 la Educación de Jóvenes y Adultos estuvo muy lejos de ser prioridad en la agenda política. No formó parte de los debates reformistas (ni técnicos ni económicos) ni hubo definiciones sobre su organización y objetivos específicos lo cual generó fragmentación y desarticulación a nivel nacional, provincial e intraprovincial. Esto contrasta con lo que sucedió en el resto del sistema educativo, donde la reforma impactó profundamente sobre la estructura y la organización curricular.

En la Ley Federal de Educación la EJA tampoco tuvo especificidad alguna, compartiendo con la Educación Especial y la Educación Artística el Capitulo VII Regímenes Especiales. La situación de postergación y abandono de la EJA agravó más aún la situación sociolaboral de las personas que, al haber desertado o no haber asistido nunca a la escuela (y por lo tanto no disponer de credenciales educativas), vieron agudizadas las dificultades para acceder a puestos de trabajo en el mercado formal de la economía. A ello se le sumó la falta de políticas de vinculación entre la educación y el mundo del trabajo dejando en manos del mercado y el sector productivo las demandas de formación. En este clima, la perspectiva de empleabilidad ${ }^{7}$ se convirtió en la matriz de los componentes de formación incluidos en los programas para desocupados, minimizando a la formación general/ escolar e imprimiendo una perspectiva meritocrática que llevaba implícito que la desocupación se explicaba por la falta de formación. En términos generales sostenemos que la década del 90 en Argentina es sinónimo de desmantelamiento del Estado y sus instituciones e impulso liso y llano de desprestigio hacia la política y los derechos sociales con el fin de despojarlos de su contenido político para transformarlos en mercancías intercambiables en el mercado. Sin embargo, A pesar de lo adverso del escenario, la comunidad educativa, los sindicatos docentes y los pedagogos e intelectuales críticos, entre otros actores, plantearon fuertes resistencias marcándole límites precisos a la derecha.

\section{Tercer momento: 2001-2015 estallido social y nuevo milenio}

Hacia mediados del año 2001 la situación política, económica, laboral y social en Argentina había llegado a un punto crítico. El 37.3\% de la población se encontraba por debajo de la línea de pobreza mientras la tasa de desempleo alcanzó el $18.3 \%{ }^{8}$. A la clase media y algunos

\footnotetext{
7 Ver Levy (2007).

${ }^{8}$ Encuesta Permanente de Hogares (EPH)-Instituto Nacional de Estadística y Censo-INDEC), onda octubre de 2001.
} 
sectores altos los bancos, con anuencia del Ministerio de Economía, les incautaron compulsivamente los depósitos bancarios a través de una medida conocida como "corralito bancario". Fue una medida que determinó la restricción para disponer de dinero en efectivo de plazos fijos, cuentas y cajas de ahorros lesionando la credibilidad del derecho a la propiedad. Estos acontecimientos, sumados a los 10 años de política de ajuste y múltiples casos de corrupción, mostraban la visible debilidad del gobierno. Así, las jornadas del 19 y 20 de diciembre de $2001^{9}$ fueron decisivas para la institucionalidad de la Argentina. Los episodios de violencia, descontento y represión policial se repitieron en las grandes ciudades donde participaron organizaciones políticas y de desocupados, ahorristas, manifestantes independientes, entre otros, Fue un momento de inflexión y desencanto con lo que popularmente se denominó la "vieja política", acuñándose el slogan "que se vayan todos" en referencia a los políticos (funcionarios y legisladores) ${ }^{10}$.

El 21 de diciembre renunció el Presidente de la Nación, Dr. Fernando De la Rúa dejando al país con el $54 \%$ de pobreza y $21 \%$ de desempleo. La Argentina del 2001 era un país sumergido en una crisis de legitimidad política. Las fuerzas tradicionales habían mostrado debilidad frente a las imposiciones del FMI repitiendo recetas condenadas al fracaso. La focalización en la pobreza sólo retrasó la fecha del estallido social y la huida en helicóptero ya es una postal de la decadencia e inoperancia del gobierno de Fernando De la Rua. El 1 de enero de 2002 asumió a la presidencia el senador Eduardo Duhalde cuyo mandato duraría sólo hasta el 25 de mayo de 2003 cuando fue electo presidente el Dr. Néstor Kirchner (2003-2007) ${ }^{11}$.

A partir de entonces se sucedieron tres mandatos presidenciales del mismo signo político, siendo los dos últimos los de Cristina Fernández de Kirchner (ex senadora nacional por la Provincia de Santa Cruz, reelecta como presidenta en 2011 por el 54\% de la población). Los tres períodos Kirchneristas mantuvieron la misma línea política, aunque con matices definidos por la coyuntura nacional y mundial. Hay autores que consideran a la etapa que comienza a partir de 2001-2002 "abre nuevos interrogantes que, al recuperar la dimensión política del discurso y del quehacer educativo, parecen responder [...] a las urgencias para abordar la complejidad del contexto sociopolítico, en términos de necesidades postergadas

\footnotetext{
9 Jornadas también conocidas como El Argentinazo donde se sucedieron protestas populares que derivaron en la renuncia del Presidente de la Nación, Fernando de la Rua.

${ }^{10}$ Lo paradójico fue que al poco tiempo, en 2003 , se realizaron las elecciones - legislativa y presidencial - y volvieron a ser electos en su mayoría los mismos que en 2001 estaban ejerciendo diferentes cargos.

${ }^{11}$ Entre la renuncia de De la Rua y la asunción de Duhalde, ocuparon el cargo: Ramón Puerta, Adolfo Rodríguez Saa y Eduardo Caamaño.
}

y de satisfacción de demanda des de actores sociales" (SENÉN GONZÁLEZ, 2008, p. 94).

Esta autora sostiene que se produjo un cambio en la mirada sobre los problemas de la educación que superó el enfoque técnico de la década anterior apuntando a dar respuestas desde la dimensión política para lo cual fue necesario crear los resortes legales necesarios para resolver los problemas pendientes. Afirma que cada una de las leyes que se sancionaron en el periodo respondió a las "urgencias del contexto social y político" (SENÉN GONZÁLEZ, 2008, p.95). Consideramos que los tres gobiernos del período 2003-2015 marcaron una ruptura en relación a las políticas de los últimos 25 años del siglo XX. Si bien faltó profundizar algunas medidas, mejorar otras o redireccionar algunas, lo concreto es que durante 12 años se generó en Argentina un importante proceso de restitución y profundización de derechos sociales, recuperación de la soberanía económica y política, trabajo conjunto con los países de la región y recuperación del Estado Nacional como actor centrar en la predistribución secundaria del ingreso No se resolvieron todos los problemas, incluso algunos no se enfrentaron, pero se puede sostener que hubo un cambio de paradigma político, social, económico y cultural que marcó grandes diferencias con los gobiernos que se sucedieron desde el 76 en adelante ${ }^{12}$. Estos cambios y avances en materia de justicia social fueron y son resistidos y combatidos por los sectores que representan el poder económico concentrado y a la derecha conservadora, que caracterizó la etapa como un retroceso en la escena internacional (EEUU y Europa), fomentó el populismo (desde una connotación negativa), y ofendió a los represores de la ultima dictadura quienes fueron juzgados y condenados por delitos de lesa humanidad.

\section{Cuarto momento: la EJA entre 2003 y 2015}

El sistema educativo hasta 2004 continuó regulado por las leyes de la década del 90 cuando la presión,

\footnotetext{
${ }^{12}$ A modo de lista no exhaustiva, las siguientes son algunas de las principales políticas de la etapa 2003-2015: Derechos Humanos: Derogación de las "Leyes del perdón", Memoria, Verdad y Justicia, reactivación de los Juicios a los genocidas. Ampliación de derechos sociales: Asignación Universal por Hijo, Ley de Matrimonio Igualitario, Ley de identidad de género, Ley contra la violencia de género, Ley de Servicios de Comunicación Audiovisual, Legislación sobre el trabajo infantil. Economía: Recuperación de empresas nacionales: YPF, agua, correo y aerolíneas. Soberanía económica y pago de la deuda al FMI. Integración Latinoamericana y Rechazo al ALCA. Estatización del sistema previsional. Política de control de precios (inflación). Creación de empleo (reducción del desempleo del $17 \%$ al 6,9 en 2013), Reducción de la pobreza $(6,5 \%$ en 2013). Educación: Derogación de leyes de los 90 y sanción de nuevas leyes, Programas Nacionales de educación, Políticas de Formación Docente, Políticas de Educación secundaria, Políticas de educación técnico profesional, Financiamiento educativo, Programas de inclusión socioeducativa, Distribución de computadoras, Creación de Universidades Nacionales, Aumento salarial a través de negociación paritaria.
} 
sobre todo por parte de los gremios docentes, puso en agenda la necesidad de iniciar un proceso de creación de nuevas normativas. Se sancionaron varias leyes, pero tres fueron las que impactaron en la EJA, promoviendo la jerarquización, el financiamiento específico y la vinculación con el mundo del trabajo. La Ley de Educación Técnico-Profesional 26.058/06 hace referencia a la articulación de las diversas ofertas de la EJA y el mundo del trabajo (Art 19), la Ley de Financiamiento Educativo 26.075/06 ubica a la modalidad como una de las once prioridades del financiamiento del sector y la Ley de Educación Nacional 26.206/06 (LEN) establece que la EJA se convierta en una de las ocho modalidades del sistema educativo (Art. 17) ${ }^{13}$. La LEN también posibilitó la creación de programas y planes a término (con fechas de inicio y cierre) destinados a abordar problemas coyunturales (art. 138). De este modo se tomaron como referencia los datos del Censo 2001 que mostraba que sobre un total de 36.260.130 de habitantes del país, cinco millones no completaron la educación secundaria (18\%) y cuatro millones no terminaron los estudios primarios (11\%) (y con la intención explícita de recrear la mística político- pedagógica de la década del 70) se crearon dos programas nacionales: Programa de Alfabetización y Educación Básica "Encuentro" en $2004^{14}$ y el Plan Nacional de Finalización de Estudios Secundarios FinEs en 2008 (luego se amplió a estudios primarios también).

El Programa Encuentro fue una iniciativa conjunta entre el Estado y oficina regional Buenos Aires de la Organización de Estados Iberoamericanos (OEI). Si bien ya existían otros programas de alfabetización ${ }^{15}$, la creación del Programa "Encuentro" reinstaló la posibilidad de la intervención estatal en ese ámbito de la EJA. A pesar que los datos mostraban que los índices de analfabetismo no eran alarmantes en comparación con otros países de la región ${ }^{16}$, sí daban cuenta de un retroceso importante de

\footnotetext{
${ }^{13}$ Según la LEN Son modalidades del sistema educativo la Educación Técnico Profesional, la Educación Artística, la Educación Especial, la Educación Permanente de Jóvenes y Adultos, la Educación Rural, la Educación Intercultural Bilingüe, la Educación en Contextos de Privación de Libertad y la Educación Domiciliaria y Hospitalaria" (LEN, art. 17). Si bien coincidimos con la importancia de la jerarquización de la EJA, Rodríguez señala que el nuevo carácter de modalidad la ubica en un mismo contexto que las otras modalidades donde se desdibuja ya que con varias de ellas tiene puntos en común (RODRÍGUEZ, 2008).

${ }^{14}$ El Programa Encuentro se creó en 2004 pero con la sanción de la Ley de Educación Nacional en 2006 quedó enmarcado en el artículo 138.

${ }^{15}$ El Programa cubano "Yo si puedo" estaba siendo implementado por varias organizaciones políticas y no gubernamentales en diferentes barrios de todo el país. Algunas de dichas organizaciones se sumaron al poco tiempo al programa oficial.

${ }_{16}$ Perú $11,4 \%$; Paraguay 9,4\%; Nicaragua 22,2\%; Honduras 18,7\%; México 9,8\%; Guatemala 31, 7\%; El Salvador 19,2\%; Ecuador 8,8\%; Chile 4\%; Brasil 12, 4\%; Bolivia 13, 8\%. Fuente: Base de datos de Sistema de Información de Tendencias Educativas de América Latina (SITEAL) (2010) construida en base a la información oficial proporcionada por: Fuentes utilizadas: Argentina Urbano - EPH/INDEC; Bolivia - EIH/INE; Brasil - PNAD/IBGE; Colombia - ECH/DANE; Chile -
}

los logros alcanzados a mediados del siglo XX cuando la educación primaria llegó casi a universalizarse mientras los sectores medios pujaron por el acceso a la educación secundaria.

El Plan FinEs es un programa de alcance nacional que fue creado para ejecutarse durante el período 2008-2011 y está destinado a atender a poblaciones de jóvenes y adultos que no finalizaron la educación secundaria (hasta 2015 finalizaron 650.000 personas los estudios secundarios). Dicho nivel se transformó en obligatorio desde 2006 a partir de la vigencia de la Ley de Educación Nacional. La implementación del Plan apuntó a la creación de ofertas educativas flexibles basadas en una estructura curricular modular acorde a las necesidades de los jóvenes y adultos, así como también otorgar certificados parciales y acreditar los saberes adquiridos a través de la experiencia y el trabajo.

Creemos que la etapa kirchnerista (2003-2015) implicó una importante apertura del campo de acción de la EJA cuyo antecedente más parecido fue la experiencia de 1973 de la DINEA. El contexto político latinoamericano de entonces era diferente, las utopías otras y las organizaciones sociales y políticas aun no habían sufrido la persecución, tortura y desaparición a manos de la dictadura, no obstante, un punto en común fue la politización y participación de la militancia, sobre todo los jóvenes, que encontraron en los primeros años del siglo XXI la esperanza de cambiar las injusticias del modelo de producción capitalista en su fase salvaje, su fase neoliberal.

\section{ACTUALIDAD Y EDUCACIÓN EN ARgentina}

En diciembre de 2015, asumió a la presidencia de la Nación la Alianza Cambiemos ${ }^{17}$, encabezada por el Ingeniero Mauricio Macri, cuya experiencia política anterior fue ser el Jefe de Gobierno de la Ciudad de Buenos Aires, la más rica del país y una de las más desiguales. El nuevo gobierno al asumir dejó claro que nada de lo realizado por el gobierno anterior coincidía con su idea de país y que por lo tanto las políticas del kirchnerismo pasaban a convertirse en lo que denominaron "pesada herencia", una especie de operación discursiva que justificaba el nombre de la alianza de gobierno. Cambiemos comenzó aplicando estrictas medidas

CASEN/MIDEPLAN; Ecuador - EESD/INEC; El Salvador - EHPM/ DIGESTYC; Guatemala - ENCOVI/INE; Honduras - EPHPM/INE; México - ENIGH/INEGI; Nicaragua - ENMNV/INIDE; Paraguay EPH/DGEEC; Perú - ENAHO/INEI; República Dominicana - ENFT/ Banco Central; Uruguay - ECH/INE.

${ }^{17}$ Coalición política de centro derecha entre el tradicional Partido Radical, el PRO y otras expresiones menores de la política argentina. Se creó en 2015 para competir en las elecciones presidenciales ganando las mismas. 
económicas de corte neoliberal que, derivaron en muy poco tiempo en un proceso inflacionario sin control (51,3\% en 2018 según los datos oficiales).

El ajuste fiscal y el recorte del gasto público, sumado a la devaluación del peso y al endeudamiento externo, nuevamente con el FMI, generó despidos masivos y suspensiones de trabajadores públicos y privados, quiebra de pequeñas y medianas empresas, pobreza e indigencia. Como en los 90, se avanzó en las reformas sectoriales: provisional (aprobada en 2017) y laboral (en proceso de aprobación) a las que se le suman la derogación de normativas como la paritaria docente (2005) y la Ley de Servicios de comunicación audiovisual del año 2009, entre otras. La reprivatización de empresas estatales, la desactivación de programas sociales, las reformas sectoriales y cierre de ministerios de Trabajo y Salud, Cultura, Ciencia y Tecnología (convertidos en secretarias) son parte constitutiva de las medidas del gobierno para desterrar la "pesada herencia".

En el ámbito educativo se avanzó en el vaciamiento y suspensión de políticas de inclusión socioeducativas, mientras que el recorte presupuestario impactó negativamente sobre el salario docente, la infraestructura, la investigación, la ciencia y la tecnología. También el ajuste económico incidió en el funcionamiento normal de las Universidades Nacionales más nuevas donde estudian jóvenes que en su mayoría son primera generación de estudiantes universitarios. La estigmatización de los docentes como vagos y sin formación volvió a ser parte del diagnostico oficial como en los 90 (GENTILLI, 1998).

En relación a la Educación de Jóvenes y Adultos, los programas "Encuentro" y "Fines" dejaron de constituir una política nacional pasando a ser experiencias dependientes de los Estados provinciales o iniciativas de las organizaciones sociales con militancia territorial en barrios cadenciados. El número de centros educativos ha disminuido considerablemente y el presupuesto es escaso o nulo. No se avanzó en políticas de formación docentes para la modalidad ni en el vínculo con el mundo del trabajo. Podemos decir que las políticas para la EJA del gobierno de Cambiemos se basan en el abandono e invisibilización explícita del área, el reemplazo del discurso y la concepción de la educación como derecho social por el de beneficio, instalando un fuerte estigma meritocrático y culpabilizador hacia los expulsados del sistema educativo.

Entendemos que se trata de políticas que apuntan a la mercantilización de la educación basadas en la falacia de la despolitización de los derechos sociales intentando convertirlos en una mercancía más que distribuye el mercado. Creemos que los derechos per se son políticos, sino no son derechos y, en el caso de la educación más aun porque, desde las perspectivas de la pedagogía y la sociología crítica entendemos que la educación no se mide por los resultados económicos sino por sus efectos sociales $\mathrm{y}$ culturales los cuales no tienen valor mercantil. Sabemos que la batalla pedagógica y cultural es siempre una batalla política cuyo objetivo es contrarrestar los efectos de la naturalización de las desigualdades instalada desde los medios que transmiten los discursos hegemónicos (LEVY, 2018). Siguiendo a Apple (1993), la derecha fue capaz de instalar un nuevo acuerdo hegemónico que integra perspectivas que no son congruentes o que incluso son contradictorias, combinando elementos nuevos y antiguos. En términos del autor:

La derecha se ha propuesto la inmensa tarea de crear una autentica "ideología orgánica", que trata de introducir en toda la sociedad y crear una nueva forma de "voluntad nacional popular". Trata de intervenir en el terreno del sentido común ordinario y contradictorio, interrumpir, renovar y transformar en una dirección mas sistemática la conciencia práctica de la gente. (APPLE, 1993, p. 37).

\section{ConClusiones: REFLEXIONES PROVISORIAS EN UN ESCENARIO CAMBIANTE}

Este trabajo pretendió ser una invitación para reflexionar sobre el rol del Estado, sobre cómo inciden las decisiones políticas en el ejercicio de los derechos sociales y sobre las consecuencias educativas del paradigma "menos Estado más mercado" en países con economías frágiles y dependientes. Para eso se recuperaron algunos procesos y proyectos político-pedagógicos que atravesaron la historia reciente de la educación de jóvenes y adultos en Argentina (principios de los años 70 en adelante) y se retomaron definiciones conceptuales sobre la modalidad y sus sujetos, así como también se mencionaron experiencias concretas (DINEA, Programa de Alfabetización Encuentro, Plan Fines). En estas palabras finales se plasman sin disimulo posicionamientos que discuten con el paradigma con la mercantilización de los derechos sociales y la educación para el mercado a partir de la convicción de que las decisiones económicas son siempre decisiones políticas, no al revés.

En Argentina, aunque se puede generalizar a otros países de la región, estamos frente a un Estado que procura desligarse (y desprestigiar también) de su responsabilidad sobre la educación pública a pesar de las enormes deudas educativas que aun tenemos sobre todo con los más postergados entre los que se encuentran los jóvenes y adultos sin escolaridad o con escolaridad obligatoria inconclusa. A eso hay que sumarle las demandas de justicia social a las que el Estado parece no escuchar o al menos 
no logra responder. La derecha, aunque democrática, nos quiere convencer que es el mercado el que va a resolver las enormes brechas entre ricos y pobres, entre ciudadanos de primera y los que quedan en las márgenes a la espera de alguna dádiva o beneficio. Así, la estigmatización de los pobres parece ser doble: están postergados mientras que el discurso oficial los culpabiliza por su situación y los obliga a mostrarse "merecedores" de ayuda. Este nuevo giro hacia la mercantilización de los derechos obstaculiza el desarrollo del pensamiento crítico y la construcción de ciudadanía de todos y todas. La ilusión del éxito individual, del ser emprendedor para triunfar, el desplazamiento de la solidaridad hacia el terreno del individualismo son los significantes que están detrás de la construcción del sentido común al que hace referencia Apple cuando explica por qué triunfa la derecha (1993). Hoy varias democracias latinoamericanas están experimentando procesos de violencia física y simbólica que, paradójicamente y a diferencia de los años 60 y 70 , no son expresiones de gobiernos de facto sino de gestiones políticas surgidas del voto popular. Muchos nos preguntamos por qué los pueblos que ya han padecido las dictaduras hoy eligen estos gobiernos que, sin demasiado disimulo, suspenden garantías constitucionales, encarcelan opositores, callan a los medios de comunicación no oficialistas, se endeudan y desfinancian la educación y la salud pública, con el mensaje de "imponer orden y desterrar la corrupción" de los gobiernos populares precedentes. Podríamos seguir enumerando situaciones y la pregunta sigue siendo la misma ¿Cuál es el mensaje que reciben las mayorías para elegir lo que las perjudica?

Desde la EJA el trabajo de reconstrucción de estos significados es un imperativo. Desnaturalizar que el fracaso y la falta de oportunidades no es un asunto personal sino que está inscripto en la matriz excluyente del modelo neoliberal, es un trabajo que debe darse dentro de las aulas y fuera de ellas, con los estudiantes y en la formación docente, en los barrios y en los centros de alfabetización, en las fábricas y en los sindicatos. No podemos postergar esta tarea porque es, sencillamente, la tarea central que tenemos como educadores, esto es poner en evidencia el sentido vedado, lo no dicho, de la violencia del mercado. Nos referimos a la igualdad ante a la ley y la desigualdad frente al capital que excluye naturalizando la diferencia.

\section{REFERENCIAS}

APPLE, M. El conocimiento oficial: la educación democrática en una era conservadora. Barcelona: Paidós, 1993.

BAUDELOT, C.; ESTABLET, R. La escuela capitalista en Francia. México: Siglo XXI, 1971.
BRASLAVSKY, C. La discriminación educativa en Argentina. Buenos Aires: Grupo Editor Latinoamericano, 1985.

CABRERA, M. El campo de la educación de adultos. Su diversidad conceptual y política. In: BRUSILOVSKY, S. (comp.). Educación escolar de adultos: una identidad en construcción. Buenos Aires: Noveduc, 2006. https://doi. org/10.26820/recimundo/1.5.2017.288-302

DE LA FARE, M. Principales ideas, discusiones y producciones en educación de jóvenes y adultos en Argentina: aportes para una reconstrucción histórica. Buenos Aires: Ministerio de Educación de la Nación, 2010. https:// doi.org/10.25145/c.educomp.2018.16.018

DE LA FARE, M.; VILLELA PEREIRA, M. Educación de jóvenes y adultos políticas educativas nacionales y experiencias de educación popular en Argentina y Brasil en los años 60 e inicios de los 70 . Revista Interamericana de Educación de Adultos, Pátzcuaro, v. 33, n. 3, p. 6-24, 2011. https://doi.org/10.24933/horizontes.v34i3.366

DE LELLA, C. Formación docente: el modelo hermenéutico reflexivo y la práctica profesional. Decisio: Saberes para la Acción en Educación de Adultos, Pátzcuaro, n. 5, p. 20-24, 2003. https://doi.org/10.35376/10324/9138

GENTILLI, P. El consenso de Washington y la crisis de la educación en América Latina. In: ALVAREZ URÍA, F. et al. (comp.). Neoliberalismo versus democracia. Madrid: La Piqueta, 1998. https://doi.org/10.31819/978396456 4450-008

GÓMEZ, M. CREAR: la palabra recuperada. In: FINNEGAN, F. (comp.). Educación de jóvenes y adultos: políticas, instituciones y prácticas. Buenos Aires: Aique, 2012.

GRAMSCI, A. La alternativa pedagógica. Barcelona: Fontanarrosa, 1981.

LEVY, E. Desafíos políticos de la educación de jóvenes y adultos: articulaciones posibles con la formación para el trabajo. In: FINNEGAN, F. (comp.). Educación de jóvenes y adultos: políticas, instituciones y prácticas. Buenos Aires: Aique, 2012. https://doi.org/10.15600/2236-9767/impulso. v19n48p7-17

LEVY, E. Educación de Adultos y formación para el trabajo en Argentina (2002-2007): una mirada desde las políticas sociales. 2013. Tesis (Doctorado) Facultad de Filosofía y Letras, Universidad de Buenos Aires, Buenos Aires, 2013. https://doi.org/10.20319/ pijss.2017.32.20152033

LEVY, E. Las políticas públicas de formación de trabajadores y la educación de jóvenes y adultos: el caso argentino en la era neoliberal. Revista Educación y Trabajo, [s. l.], n. 1, 2007. https://doi.org/10.24236/24631388.n3.2016.628

LEVY, E. Políticas educativas con objetivos de mercado: el caso de Argentina en la actualidad. In: CONGRESO 
INTERNACIONAL DE LA ASOCIACIÓN DE ESTUDIOS LATINOAMERICANOS, 36., 2018, Barcelona. Anais [...]. Barcelona: [s. n.], 2018. https://doi.org/10.5354/07196296.2017 .46353

PUIGGROS, A. ¿Qué pasó en la educación argentina? Breve historia desde la conquista hasta el presente. Buenos Aires: Galerna, 1998.

RODRÍGUEZ, L. Educación de adultos y actualidad: algunos elementos para la reflexión. Revista del Instituto de Investigaciones en Ciencias de la Educación, Buenos Aires, v. 5, n. 8, 1996. Disponível em: https://noformal.blogspot. com/2006/10/rodrguez-lidia-educacin-de-adultos-y.html. Acesso em: 17 out. 2019. https://doi.org/10.25145/ c.educomp.2018.16.018

RODRÍGUEZ, L. Pedagogía de la liberación y educación de adultos. In: PUIGGRÓS, A. (dir.). Dictaduras y utopías en la historia reciente de la educación Argentina (1955-1983). Buenos Aires: Galerna, 1997. https://doi. org $/ 10.35537 / 10915 / 55151$

RODRÍGUEZ, L. Situación presente de la educación de las personas jóvenes y adultas en América Latina y el Caribe. Mexico: CREFAL, 2008.

SENEN GONZALEZ, S. Políticas, leyes y educación: entre la regulación y los desafíos de la macro y la micropolítica. In: PERAZZA, R. (comp.). Pensar en lo público: notas sobre la educación y el Estado. Buenos Aires: Aique, 2008. https:// doi.org/10.15517/revedu.v37i2.12929

WANSCHELBAUM, C. El olvido está lleno de memoria: las políticas de Educación de Jóvenes y Adultos durante el gobierno de Alfonsín (1983-1989): un estudio de caso: el Plan Nacional de Alfabetización. 2012. Tesis (Doctorado) - Facultad de Filosofía y Letras, Universidad de Buenos Aires, Buenos Aires, 2012. https://doi.org/10.25145/j. pasos.2017.4.009

Recibido en: 16/4/2019

Aprobado en: 4/9/2019.

Publicado en: 20/11/2019.

Dirección postal:

Esther Levy

Patricias Argentinas 151 9D

CP 1405

Ciudad Autónoma de Buenos Aires, Argentina

\section{Autora:}

ESTHER LeVY

Doctora en Ciencias de la Educación, Universidad de Buenos Aires (UBA) Argentina. Profesora de Pedagogía y Educación de Jóvenes y Adultos (UBA), Argentina.

Orcid: http://orcid.org/0000-0003-3124-0085

E-mail: estherlevy01@gmail.com 